\title{
Sucrose Octasulfate Stimulates Gastric Somatostatin Release
}

Michael R. Lucey, M.D., Jung Park, M.Sc., John DelValle, M.D., Li Dong Wang, M.Sc.,

TADATAKa YamadA, M.D., Ann Arbor, Michigan

To explore the mechanisms of the effects of sucralfate on the stomach, we investigated the action of sucrose octasulfate (SOS), a constituent of sucralfate, on the function of canine gastric parietal cells and somatostatin cells and in the isolated perfused intact rat stomach. Somatostatin cells from the canine gastric fundus were isolated by EDTA-collagenase dispersion and counterflow elutriation, and somatostatin-like immunoreactivity (SLI) release in response to SOS was measured by radioimmunoassay. Similar methods were used to isolate gastric parietal cells, in which gastric acid secretion was measured by uptake of a radiolabeled weak base, $\left[{ }^{14} \mathrm{C}\right]$ aminopyrine. SLI release by the intact rat stomach was examined in an isolated vascularly perfused rat stomach model. SOS, either alone or co-administered with epinephrine or gastrin heptadecapeptide (G17), dose-dependently stimulated SLI release by isolated canine fundic D-cells. At the highest doses, SOS potentiated the effect of epinephrine but not G17. Similarly, SOS potentiated the stimulating effect of dibutyryl cyclic adenosine $3^{\prime}, 5^{\prime}$-monophosphate (DBcAMP), but not 12- 0 -tetradecanoylphorbol 13 -acetate (TPA). The effect of SOS on SLI release could be inhibited by octreotide, a somatostatin analogue. SOS did not alter acid secretion by cultured canine parietal cells either in the basal state or when coadministered with acid secretagogues. In isolated perfused rat stomach studies, SOS produced a significant $(60 \%$ greater than basal) increase in SLI secretion. There was a similar effect when SOS was perfused against a background of isoproterenol. SOS stimulates SLI release from gastric somatostatin cells and from the isolated perfused stomach but has no direct effect on gastric

\footnotetext{
From the Department of Internal Medicine, University of Michigan Medical Center, Ann Arbor, Michigan.

These studies were supported by grant NIH RO1DK33500 and funds from the University of Michigan Gastrointestinal Peptide Research Center (grant P30DK34933).

Requests for reprints should be addressed to Tadataka Yamada, M.D., 3912 Taubman Center, University of Michigan Medical Center, Ann Arbor, Michigan 48109-0362
}

parietal cells. These actions of SOS may mediate in part the apparent ability of sucralfate to enhance gastric mucosal defense.

Qucralfate, an aluminum salt of the sulfated disaccharide, sucrose octasulfate (SOS), promotes healing of experimentally induced gastric ulcers in animals and spontaneous duodenal ulcers in humans $[1,2]$. Among the mechanisms that have been proposed to account for these cytoprotective effects are increased secretion of gastric mucus, alteration of the physiochemical and, thereby, protective properties of mucus, local release of prostaglandin, reduction of gastric pepsin activity, absorption of bile salts, and direct binding to mucosa [3-8]. However, neither sucralfate nor SOS, its presumed active constituent, is known to influence the secretion of gastric acid or regulatory peptides by the stomach. One of these regulatory peptides, somatostatin, is a major local regulator of gastric physiology, modulating acid secretion, endocrine function, and probably blood flow [9]. For these reasons, somatostatin has been proposed as having an important role in regulation of ulcer healing [10]. We undertook these studies, therefore, to examine whether SOS may exert its ulcer-healing effects in part via release of endogenous gastric somatostatin.

\section{METHODS}

\section{Isolated Cell Studies}

Cells were dispersed from freshly obtained adult canine gastric mucosa as reported previously $[11,12]$. Briefly, the stomachs were divided into fundic and antral segments and the fundic mucosa was bluntly separated from the submucosa. Mucosal fragments were incubated sequentially in collagenase $[0.35 \mathrm{mg} / \mathrm{mL}$ ) and ethylene diaminetetraacetic acid (EDTA, $1 \mathrm{mM}$ ) and the dispersed cells were separated by counterflow elutriation using a JE-10X elutriation system (Beckman Instruments, Fullerton, California). The somatostatin cell fractions were collected, then layered at a density of $2.5-3.5 \times 10^{6}$ cells/well and cultured at $37^{\circ} \mathrm{C}$ on a bed of collagen in a 24-mm multiwell tissue culture plate in $1 \mathrm{~mL}$, of Ham's F-12/Dulbecco's modified Eagle's (50:50) medium containing 10\% dialyzed 
dog serum, insulin ( $8 \mathrm{mg} / \mathrm{mL})$, hydrocortisone (1 $\mathrm{mg} / \mathrm{mL})$, and gentamicin $(100 \mu \mathrm{g} / \mathrm{mL})$ in the presence of $95 \%$ air, $5 \% \mathrm{CO}_{2}$. The fractions used for study consisted of roughly $70 \%$ somatostatincontaining D-cells on the basis of immunocytochemistry [11]. After 40 hours stabilization, the cells were incubated in Earle's balanced salt solution containing various test substances for a 2 -hour test period and the somatostatin-like immunoreactivity (SLI) released into the media was measured by radioimmunoassay [13].

Fractions enriched in parietal cells were isolated to a purity of $60-70 \%$ in similar fashion as previously described [14]. Viability of the parietal cells exceeded $95 \%$ as judged by trypan blue exclusion. We added $\left[{ }^{14} \mathrm{C}\right]$ aminopyrine $(0.1 \mu \mathrm{Ci}$, specific activity $=80 \mu \mathrm{Ci}$ per $\mu \mathrm{mol}$ ) and various test materials to a $4 \times 10^{6}$ cell suspension in $2 \mathrm{ml}$ Earle's balanced salt solution containing $N$-2-hydroxyethylpiperazine- $N^{\prime}$-2-ethanesulfonic acid (HEPES) (19 $\mathrm{m} M$ ) and bovine serum albumin $(0.1 \%)$. The mixture was gassed with $95 \% \mathrm{O}_{2}, 5 \% \mathrm{CO}_{2}$, and incubated for 20 minutes at $37^{\circ} \mathrm{C}$. Thereafter, cells were pelleted by centrifugation and accumulation of $\left[{ }^{14} \mathrm{C}\right]$ aminopyrine within the pellet was measured by scintigraphy.

\section{Gastric Perfusion Studies}

Perfusion of vascularly intact isolated rat stomachs was performed as described previously [15]. Briefly, male Sprague-Dawley rats (250-400 g) were fasted with free access to water for 16-24 hours and anesthetized by intraperitoneal administration of sodium pentobarbital. Stomachs were isolated and perfused according to the previously published modification of the technique of Grodski et al [16]. This involves dissecting the stomach free from the esophagus and duodenum and removing the pancreas, while maintaining the aortic remnant, celiac artery, and portal vein. The isolated stomachs were transferred immediately to a heated $\left(37^{\circ} \mathrm{C}\right)$ stand, whereupon the aortic remnant and portal vein were cannulated. The preparation was perfused at a rate of $3 \mathrm{~mL} /$ minute with oxygenated $\left(95 \% \mathrm{O}_{2}-5 \% \mathrm{CO}_{2}\right)$ Krebs-Ringer buffer containing $3 \%$ dextran $\mathrm{T}-40$ and $0.2 \%$ bovine serum albumin. Portal venous effluent was collected at 1-minute intervals and then stored at $-20^{\circ} \mathrm{C}$ for subsequent measurement of SLI and gastrin by radioimmunoassay [13]. In all experiments, the responsiveness of the preparation was established by administration of isoproterenol, a known secretagogue of SLI, before and after the test periods.

\section{RESULTS}

In our initial experiments we examined the effects of SOS on basal secretion of SLI as well as SLI secretion induced by epinephrine or heptadecapeptide (G17). As shown in Figure 1, SOS dose-dependently stimulated SLI secretion in all three circumstances. Of particular interest was the observation that the combined stimulatory action of SOS at the two highest doses $(10$ and $20 \mathrm{mg} / \mathrm{mL}$ ) against a background of epinephrine exceeded the sum of the SLI responses to each secretagogue administered alone. In contrast, a similar potentiating phenomenon was not observed when SOS and G17 were combined. From these data, we inferred that SOS and epinephrine may interact via separate signal transduction mechanisms. In previous studies we have shown that epinephrine stimulates canine fundic D-cells via cyclic adenosine monophosphate (cAMP) generation, whereas gastrin's effects are mediated by induction of membrane inositol phospholipid turnover and activation of protein kinase $C[17,18]$. To examine further the potential interactions of SOS with these intracellular signal transduction mechanisms, we investigated the SLI
Figure 1. The effect of sucrose octasulfate (SOS), either alone or in combination with epinephrine (EPI) or gastrin heptadecapeptide (G17), on somatostatin-like immunoreactivity (SLI) release by fundic D-cells. The data represent means \pm standard errors from four separate cell preparations.

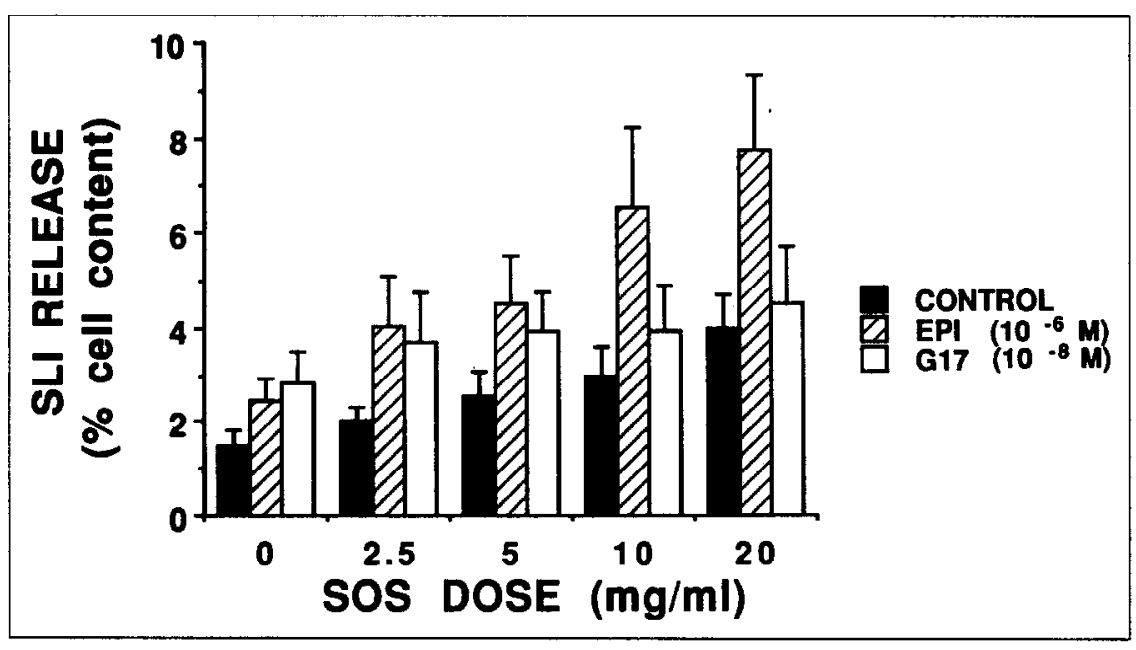



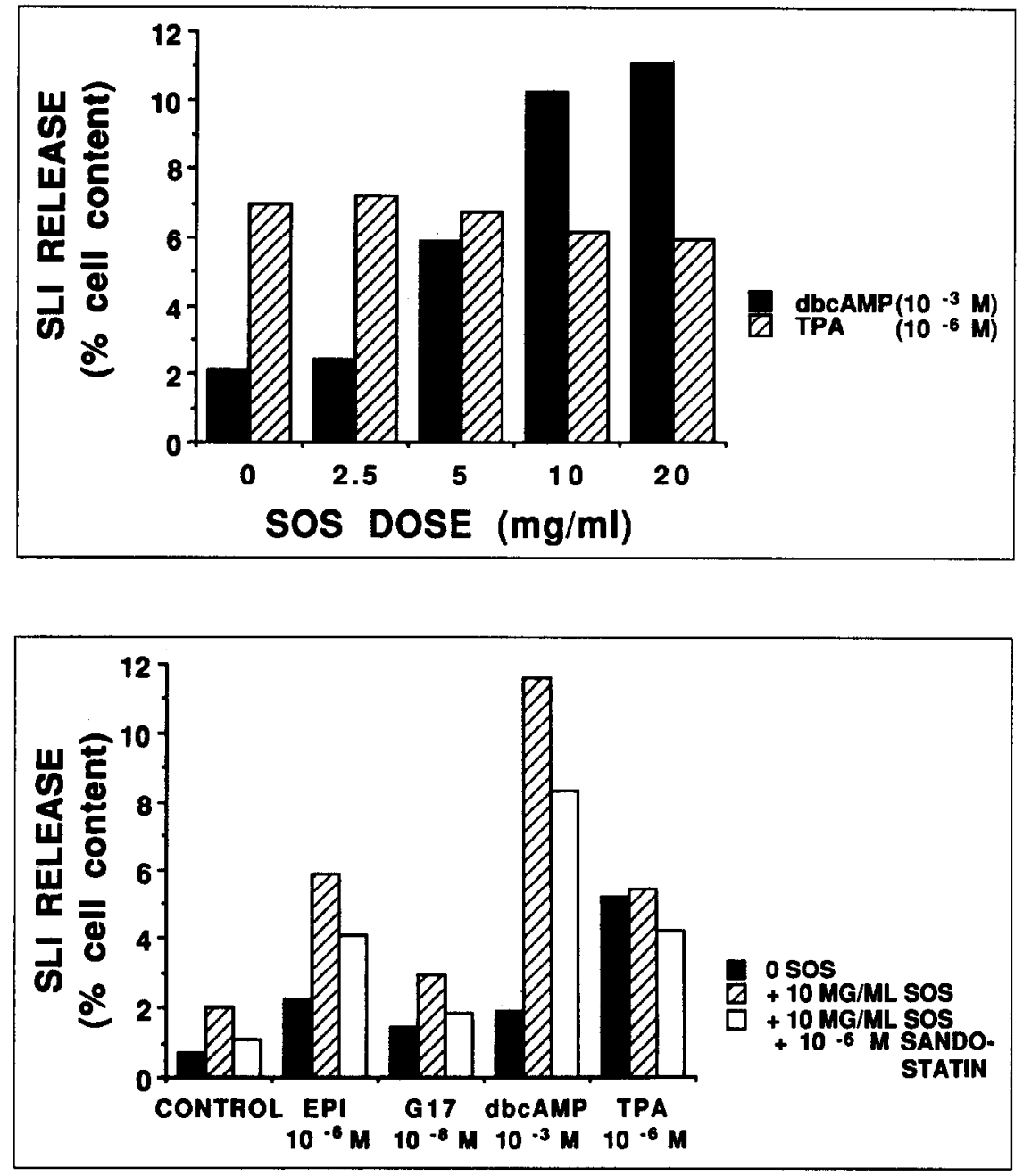

Figure 2. The effect of sucrose octasulfate (SOS), either alone or in combination with dibutyryl cyclic adenosine $3^{\prime}, 5^{\prime}$-monophosphate (DBCAMP) or 12-0-tetradecanoylphorbol-13. acetate (TPA) and somatostatin-like immunoreactivity (SLI) release by fundic D-cells. The data are from a single-cell preparation and are representative of data obtained from two other preparations.

Figure 3. The effect of octreotide (Sandostatin) on somatostatin-like immunoreactivity (SLI) release in response to sucrose octasulfate (SOS), either alone or in combination with other secretagogues. The data are from a single-cell preparation and are representative of data obtained from two other preparations.

response to combined administration of SOS and either dibutyryl cAMP (DBcAMP) or 12-Otetradecanoylphorbol 13-acetate (TPA), a direct stimulant of protein kinase C. As shown in Figure 2, SOS potentiated the SLI-stimulatory action of DBcAMP but not that of TPA.

To determine whether the effect of SOS represented nonspecific irreversible stimulation of, or possibly even damage to, D-cells, we investigated whether the stimulation of SLI release by SOS could be inhibited. As shown in Figure 3, octreotide, a functional analogue of somatostatin that is not immunoreactive in our somatostatin radioimmunoassay, inhibited at least partially the SLI-stimulating effect of SOS alone and SOS in combination with either epinephrine, G17, DBCAMP, or TPA. We also explored whether the stimulatory effect of SOS was selective for D-cells by examining its action on gastric parietal cells. As shown in Figure 4, SOS in a dose that was effective in stimulating SLI secretion did not affect aminopyrine uptake by isolated enriched parietal cells, either basally or when co-administered with acid secretagogues.
We examined whether the effects of SOS on D-cells could be reproduced in a more intact physiologic system, the isolated perfused whole stomach. As shown in Figure 5, SOS produced a modest but significant increase in basal SLI release. When SOS was administered with a background infusion of low-dose isoproterenol, a similar modest increase in SLI concentration was observed in the portal venous effluent (Figure 6).

\section{COMMENTS}

Although sucralfate has become a widely used agent to prevent or treat gastric and intestinal mucosal injury, the cellular basis of its action is uncertain. Much of the effort to determine the mechanism of sucralfate's efficacy has been focused on its ability to enhance mucosal defense. Among the factors that have been implicated in this function are the ability of sucralfate, or its active component SOS, to enhance prostaglandin production, mucus secretion and physiochemistry, and epithelial electrical potential $[3,4,8,19]$. The cells that function as targets for sucralfate or SOS have not been identified. One potential target cell is the gastric D-cell 
Figure 4. The effect of sucrose octasulfate (SOS) on uptake of radiolabeled aminopyrine by enriched canine parietal cells either alone or with coadministration of isomethylxanthine (IMX); histamine (H) plus IMX, heptadecapeptide (G17) plus IMX, and carbachol (CARB) plus IMX. The data represent means \pm standard error from three separate cell preparations.

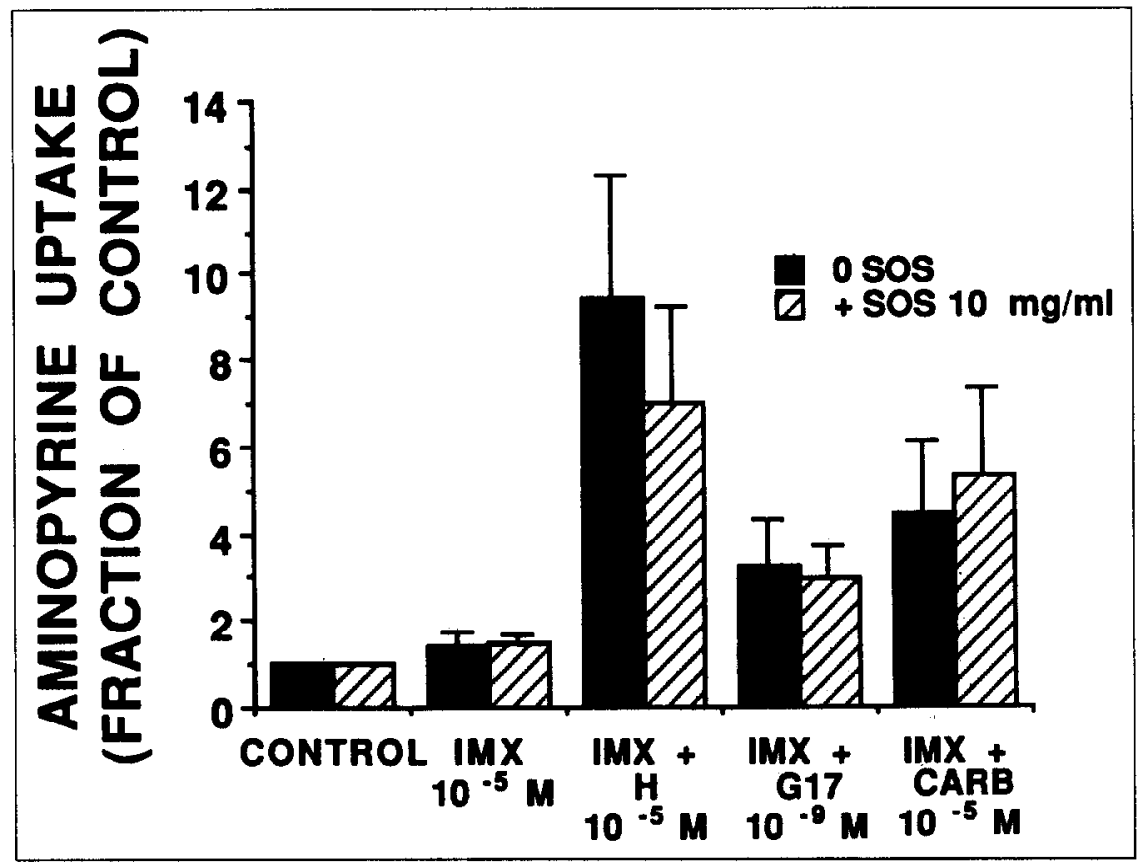

that produces somatostatin. Somatostatin has been shown previously to prevent experimentally induced gastric ulcers, and in contrast to its usual inhibitory actions, has been found to enhance gastric mucus production $[10,20]$. Our currrent studies showing that SOS stimulates SLI release from the stomach via direct action on D-cells in the gastric mucosa support the hypothesis that sucralfate may mediate its effect through somatostatin.

The action of SOS on isolated fundic D-cells resembles that of other neurohormonal stimuli of SLI release in that it is dose-dependent and potentiates the SLI response to agents that activate the cAMP messenger pathway, but influences only in additive fashion agents that act via the $\mathrm{Ca}^{2+}$ /protein kinase $\mathrm{C}$ pathway. This would imply a direct receptormediated action of SOS linked to a calcium-dependent intracellular second messenger mechanism. Further studies are necessary to define the nature of this receptor and to confirm this intracellular mode of action. Nonetheless, the action of SOS is clearly not a nonspecific phenonomen since it is reversible and D-cell selective. Moreover, it is not likely to be an artifact of the D-cell culture system, because it could be reproduced in the intact perfused stomach. However, because our D-cell preparations are not entirely pure, we cannot exclude the possibility that an intermediary target cell for SOS other than the D-cell sequentially stimulates SLI release.

The relevance of our studies to the pharmacologic action of orally ingested sucralfate requires some scrutiny. The use of SOS for our studies seems reasonable in view of the observation that sucralfate, when placed in the acid milieu of the stomach, dis- sociates into its components aluminum ions and SOS [21]. The usual therapeutic doses of sucralfate are capable of producing local concentrations of SOS in the ranges described in our studies [2.5-20 $\mathrm{mg} / \mathrm{mL}]$. Furthermore, D-cells in the gastric antrum and possibly also in the fundus are known to

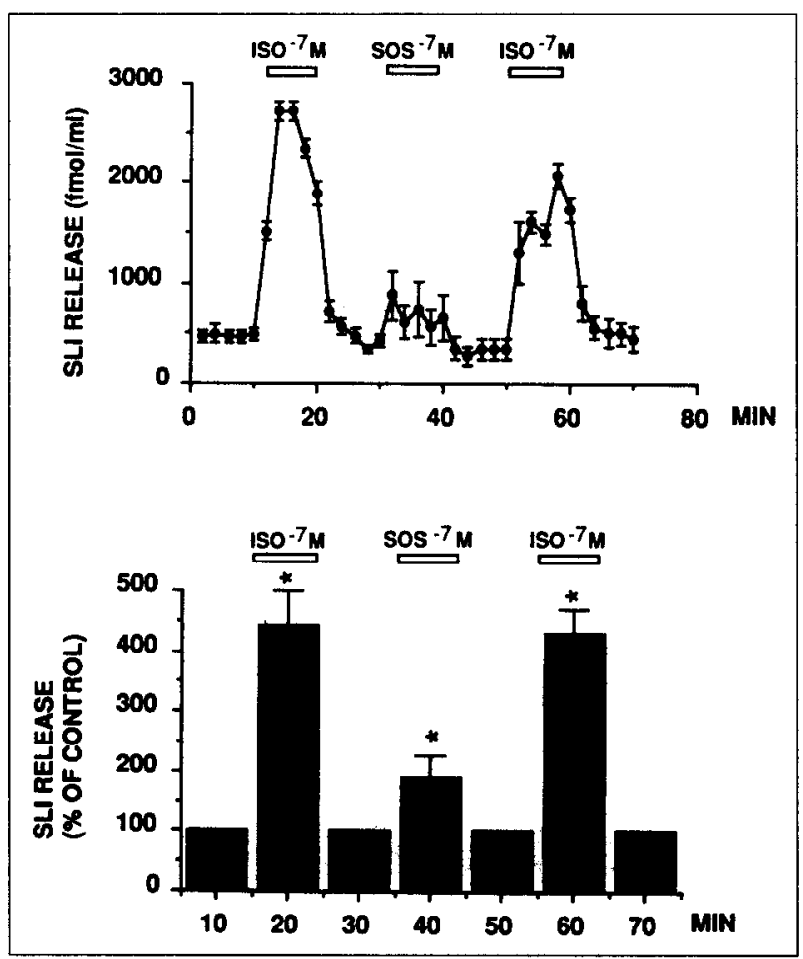

Figure 5. The effect of sucrose octasulfate (SOS) on somatostatin-like immunoreactivity (SLI) release by the isolated perfused rat stomach. Data are represented as means \pm standard error $(n=5)$ of absolute SLI concentration (top) or percentage of control (bottom). ${ }^{*} p<0.05$, compared to basal (Student's $t$-test for paired data.) $1 \mathrm{SO}=$ isoproterenol. 


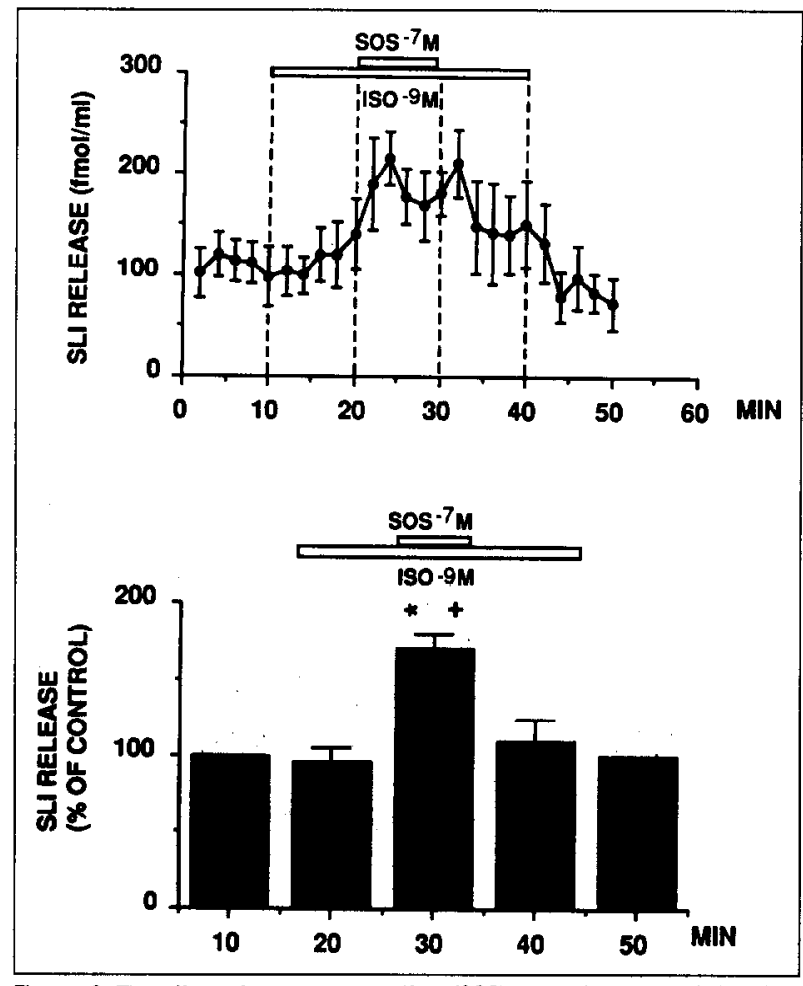

Figure 6. The effect of sucrose octasulfate (SOS) in combination with low-dose isoproterenol (ISO) $\left(10^{-9} \mathrm{M}\right.$ on somatostatin-like immunoreactivity (SLI) secretion from the isolated perfused stomach. The data, provided in the same format as in Figure 5 , represent means \pm standard error from five separate perfusions. SOS produced a response that was significantly greater than control on SLI secretion in response to low-dose isoproterenol. ${ }^{*} p<0.05$, compared to basal; $t p 0.05$, compared to isoproterenol alone. (Student's $t$-test for paired data.)

be of the "open" type; that is, they have apical membranes that extend to the lumen of the stomach [22]. Thus, D-cells are equipped to respond to stimuli present in the intragastric contents. This mechanism presumably accounts for gastric SLI release in response to intralumenal acidification [23]. Our perfused stomach studies were performed primarily to confirm the observations made in isolated gastric D-cells. In these preparations SOS was administered arterially rather than lumenally and so may not have been physiologic. However, despite the notion that sucralfate is poorly absorbed, there is evidence that a significant quantity of aluminum ions and possibly SOS also can enter the circulation when standard doses of sucralfate are administered by mouth [24]. The low doses used in the perfusion studies $\left[10^{-7} M\right)$, therefore, may be a reasonable reflection of the amounts that circulate in plasma.

Our studies provide novel insight into the cellular mechanisms by which sucralfate works as a therapeutic or cytoprotective agent in the stomach. It is consistent with the hypothesis that sucralfate, acting through its constituent moiety SOS, stimulates release of SLI, which, in turn, promotes ulcer heal- ing via a variety of mechanisms. Since virtually every other commonly used anti-ulcer therapy depends on inhibition or buffering of gastric acid, it is of note that SOS had no direct effect on acid secretion by gastric parietal cells. The remarkable evidence that SOS appears to act via specific receptormediated events to initiate SLI release from D-cells requires confirmation and further exploration.

\section{ACKNOWLEDGMENT}

We are grateful to Mrs. Muriel Fritz for typing the manuscript. Sucrose octasulfate was a generous gift of Chugai Pharmaceutical Company Limited, Tokyo, Japan. Collagenase (type 1), dibutyryl cyclic adenosine $3^{\prime}, 5^{\prime}$-monophosphate, epinephrine, isoproterenol, bovine serum albumin, and 12-0-tetradecanoylphorbol-13-acetate were purchased from Sigma Chemical (St. Louis, Missouri); HEPES, from Calbiochem-Behring (LaJolla, California); Earle's balanced salt solution (EBSS), Hank's balanced salt solution, and Ham's F-12-Dulbecco's modified Eagle's (50:50) medium were obtained from Irving Scientific (Santa Ana, California). Somatostatin octreotide was a generous gift of Sandoz Pharmaceuticals Corporation (East Hanover, New Jersey). Gastrin heptadecapeptide (G17) was produced by Peninsula Laboratories (Belmont, CA).

\section{REFERENCES}

1. Hollander $D$, Tarnawski A, Krause W, Gergely $H$. Protective effect of sucralfate against alcohol induced gastric musosal injury in the rat. Macroscopic, histologic, ultrastructural, and functional time sequence analysis. Gastroenterology 1985; 88 : 366-74.

2. : Gollander D. Efficacy of sucralfate for duodenal ulcers: a multicenter double blind trial. J Clin Gastroenterol 1981; 3 (Suppl 2): 153-7.

3. Shea-Donohue T, Steel L, Montcalm E, Dubois A. Gastric protection by sucralfate. Role of mucus and prostaglandins. Gastroenterology 1986; 91: 660-6.

4. Solomiany BL, Piotrowski J, Okazaki K, Grzelinska E, Solmiany A. Nature of the enfancement of the protective qualities of gastric mucus by sucralfate. Digestion 1989; 44: 222-31.

5. Romano M, Raxandi M, ivey $K$. Effect of sucralfate and its components on taurocholate-induced damage to rat gastric mucosal cells in tissue culture. Dig Dis Sci 1990; 35: 467-76.

6. Schweitzer EJ, Bass BL, Johnson LF, Harmon JW. Sucralfate prevents experimental peptic esophagitis in rabbits. Gastroenterology $1985 ; 88: 611-9$.

7. Graham DY, Sackman JW, Giesing DH, Runser DJ. In vitro adsorption of bile salts and aspirin to sucralfate. Dig Dis Sci 1984; 29: 402-6.

8. Tarnawski A, Hollander D, Krause WJ, Zipser RD, Stachura J, Gergely H. Does sucralfate affect the normal gastric mucosa? Histologic, ultrastructural, and functional assessment in the rat. Gastroenterology 1986; 90: 893-905.

9. Lucey MR, Yamada T. Biochemistry and physiology of gastrointestinal somatostatin. Dig Dis Sci 1989; 34: 5S-13S.

10. Zierend $H$, Hengst $K$, Wagner $H$, Gerlack $M$. Inhibition of stress ulcer formation with somatostatin in rats. Res Exp Med 1976; 168: 199-204.

11. Soll AH, Yamada T, Park J, Thomas LP. Release of somatostatin-like immunoreactivity from canine fundic mucosal cells. Am J Physiol 1984; 247: G558-66.

12. Yamada T, Soll AH, Park J, Elashoff J. Autonomic regulation of somatostatin release: studies with primary cultures of canine fundic mucosal cells. Am J Physiol 1984; 247: G567-73.

13. Yamada T, Marshak D, Basinger S, Walsh J, Morley J, Stell W. Somatostatin-like immunorectivity in the retina. Proc Natl Acad Sci USA 1980; 77: 1691-5.

14. Soll $\mathrm{AH}$. secretagogue stimulation of $[\mathrm{Cl4}]$ aminopyrine accumulation of isolated canine parletal cells. Am J Physiol 1980; 238: G366-75.

15. Martindale R, Kauffman GL, Levin S, Walsh JH, Yamada T. Differential regulation of gastrin and somatostatin secretion from isolated perfused rat stomachs. Gastroenterology 1982; 83: 240-4.

16. Grodstry $G$, Batts A, Bennett $L$, et al. Effects of carbohyarates on secretion of insulin from the pancreas. Am J Physiol 1963; 205: 628-44.

17. Chiba T, Sugano K, Park J, Yamada T. Potential mediation of somatostatin secretion from canine fundic D-cells by protein kinase C. Am J Physiol 1987; G62-7.

18. Chiba T, Park J, Yamada T. Regulation of somatostatin release from dispersed canine fundic D-cells. in: Reichlin S, ed. Somatostatin. Plenum Publishing Corpora- 
tion 1987; 229-37.

19. Orlando RC, Turjman NA, Tobey NA, Schreiner VJ, Powel DW. Mucosal protection by sucralfate and its components in acid-exposed rabbit esophagus. Gastroenterology 1987; 93: 352-61.

20. Johansson C, Aly A. Stimulation of gastric mucus output by somatostatin in man. Eur J Clin Invest 1982; 12: 37-9.

21. Nakazawa $S$, Nauashima $R$, Samloff iM. Selective binding of sucralfate to gastric ulcer in man. Dig Dis Sci 1981; 26: 297-300.
22. Fujita $T$ Kobayashi $S$. The cells and hormones of the GEP endocrine system. A cell biological approach. In: Fujita T, ed. Tokyo, Igaku Shoin, 1973; 1-16.

23. Lucey MR, Wass JAH, Rees LH, Dawson AM, Fairclough PD. Relationship between gastric acid and elevated plasma somatostatinlike immunoreactivity after a mixed meal. Gastroenterology 1989; 97: 867-72.

24. Robertson JA, Saluky IB, Goodman WG, Norris KC, Coburn JW. Sucralfate, intestinal aluminum absorption, and aluminum toxicity in a patient on dialysis. Ann Intern Med 1989; 111: 179-81. 